\title{
Modern Molecules to Keep Ancient Traditions: Ethical and Social Perspectives
}

\author{
Arencibia Rodríguez $\mathrm{AD}^{1 *}$, Lazzaro-Salazar $\mathbf{M}^{2}$, Correa Schnake $\mathbf{M}^{3}$ and Mundaca EA ${ }^{1}$ \\ ${ }^{1}$ Faculty of Agricultural and Forestry Sciences, Catholic University of Maule, Chile \\ ${ }^{2}$ Vice-Rectory for Research and Postgraduate Studies, Catholic University of Maule, Chile
}

${ }^{3}$ Faculty of Religious and Philosophical Sciences, Catholic University of Maule, Chile

Submission: December 20, 2017; Published: January 19, 2018

*Corresponding author: Ariel D Arencibia Rodríguez, Faculty of Agricultural and Forestry Sciences. Catholic University of Maule, Ave San Miguel 3605. Talca, Chile, Tel: +56712203100; Email: aarencibia@ucm.cl/arieldarencibia@gmail.com

\begin{abstract}
Bioeconomics and the development of modern nutraceutical, pharmaceutical and cosmetology industries is increasingly based on the search for active principles used ancestrally by different human cultures worldwide. In this context, the studies of identification and characterization of the so-called 'new molecules' are mainly carried out on organisms originating from both conserved and wild biodiversity, as well as from a wide spectrum of biological resources that the peasant populations have been able to maintain throughout centuries. Considering the lessons learnt in this field, the development of novel molecules related to useful functions should be focused on and stem from the experiences gained from previous approaches. Moreover, each new challenge must be subjected to ethical scrutiny where the human being plays the main role in the exploitation of biodiversity and the environment, which, as it is increasingly evident, threatens and jeopardizes the sustainable development of societies. We conclude the necessity to establish a global unified ethical perspective towards the use of biodiversity, as well of the new technological developments based in ancient human traditions
\end{abstract}

Keywords: Modern molecules; Nutraceutical industry; Sustainability; Biodiversity; Ancient traditions; Ethics

\section{The Development of Nutraceutical Industry Based on Traditional Food}

The health-promoting use of food products is an ancient practice. As an example, the consumption of fermented foods started a long time before the existence of microorganisms was discovered. The early records of this practice were provided by the Roman historian Plinio (Plinius) around 76 B.C. and were based on milks and their use in the treatment of various gastro-intestinal infections [1]. In this context, and despite the fact that the probiotic concept was formally postulated at the beginning of the 20th century, scientific evidence of probiotic action mechanisms remains a challenge, especially in the case of functional foods, which in recent years have begun to be consumed by a generally healthy population [2].

The biogenic trait of fermented functional foods derives from the microbial production and release of bioactive metabolites, i.e. certain vitamins, bioactive peptides, organic acids or fatty acids, produced at some stage of the fermentation processes [3]. In this context, the role of functional foods is to maintain the health or to improve it when it is transitorily affected. Therefore, to validate useful biomarkers for analytical purposes and robust and reliable bioassays, based on the identification and characterization of biologically active compounds and their mechanisms of action, must be standardized [2].
In this way, it is important to highlight that the probiotic concept has been developed, predominantly in the last years, through reliable and scientific facts obtained from placebocontrolled clinical trials. Results have shown that the strains of some particular microorganisms can be, for example, successfully related to positive health effects. As a consequence, today significant amounts of consumers believe that ingesting such foods might increase their chances to maintain good health and prevent diseases [3].

On the other hand, the term functional food was declared in the 1980s in Japan to refer to those food products fortified with special constituents that generate or provoke advantageous physiological effects in the consumer? [3]. Relationships among nutrition, sensory satisfaction, fortification and modulation of physiological systems support the establishment of a specific health-related food category called FOSHU (Food for Specified Health Uses), which includes the full health claims for this sort of food [4].

Carrots (Daucus carota L.), and its phenotypic variability, are an example of traditional crops with nutraceutical functions that are currently under development [5]. Despite the fact that carrots, as we know them today, display an orange color, the 
original accessions of carrots were yellow and purple. These carrots' germplasm has now been subjected to a phenotypic characterization and selection in order to increase the recovery efficiencies of beneficial metabolic compounds. This genetic improvement process, called bio fortification, has increased provitamin A content as $\alpha$ and $\beta$-carotene, in addition to the content of anthocyanins and the nonprovitamin A carotenoid lycopene, both powerful antioxidants that contribute to promoting optimal health [5].

To provide further examples, the physicochemical and nutritional characteristics of some selected fruit species have been correlated with the influence of their physiologically active compounds on human health by means of scientifically proven information. In this sense, polyphenols, flavonoids, flavanols, tannins, ascorbic acid, anthocyanins, volatile compounds, minerals and organic acids have been determined by modern phytochemical approaches and correlated with antioxidant radical scavenging assays (DPPH, FRAP, CUPRAC, ABTS and ORAC). Results showed that fruit diets (including, for example, avocado, dragon fruit, durian, kiwifruit, mango, mangosteen, persimmon and snake fruit) positively affect the plasma lipid profile, antioxidant activity as well as the histological structure of the aorta in rats fed with cholesterol-rich diets [6].

Over the last years, the production of exotic fruits, its trade and consumption have augmented considerably on the worldwide markets due to their particular sensory characteristics, as well as to the increased recognition of their nutritional and therapeutic value. The use of phytochemicals contained in these fruits allows for a broad spectrum application in the food industry including, for example, the stability and shelf life of food products [7]. In this light, systematic studies have been encouraged with the aim of doing toxicological analysis of bioactive extracts, and investigating the metabolism of bioactive compounds, their bioavailability and bio accessibility, as well as the sensorial and nutritional aspects of the food products. In this context, an analysis of the economic sustainability aspects of the extraction processes and marketing of natural bioactive extracts, must be conducted in a case-by-case manner. It is expected that the sustainable exploitation of these 'new plants' might bring not only economic benefits to producers but also have a beneficial impact on the environment, resulting in a greater diversity and availability of healthy food products [7].

Within such context, the case of berries should be highlighted at this point as they are among the most recognized types of fruits worldwide for their beneficial properties to human health. Berries are a high-quality source of polyphenols, especially anthocyanins, micronutrients and fiber. Results of epidemiological and clinical studies associated these components to, for instance, the reduction of cardiovascular risks (cita?). Several studies in chokeberries, cranberries, blueberries and strawberries (either fresh, or as juice, freeze-dried, or purified anthocyanin extracts) have confirmed increases in LDL oxidation, lipid peroxidation, total plasma antioxidant capacity, dyslipidemia and glucose metabolism [8]. Experiments showed that benefits could be observed in both healthy persons and in those with pre-existing metabolic risk factors. In this regard, the mechanisms that lead to these beneficial effects are believed to include up-regulation of endothelial nitric oxide synthase, decreased activities of carbohydrate digestive enzymes, decreased oxidative stress, and inhibition of inflammatory gene expression and foam cell formation [8]. Further studies have also? confirmed that berries are a rich source of a variety of bioactive compounds such as flavonoids, phenolics, anthocyanins, phenolic acids, stilbenes and tannins, as well as nutritive compounds such as sugars, essential oils, carotenoids, vitamins and minerals. Bioactive compounds from berries have demonstrated effective antioxidant, anticancer, anti-mutagenic, anti-microbial, anti-inflammatory, and antineurodegenerative properties, both in vitro and in vivo trials [9].

As evidenced in the previous examples, in recent years the nutraceutical industry has used biological accessions which, for generations, have been used naturally for human food purposes. In this sense, thanks to the development of modern and efficient technologies, the biologically active principles of this biodiversity can now be isolated and reformulated in attractive commercial presentations. This, however, has been done in spite of the fact that in many cases there is still no scientific evidence to validate the nutraceutical properties related to the molecules that they are being isolated and formulated, beyond their natural phytochemical composition (metabolic spectrum).

\section{Modern Pharmaceutical Industry Takes Advantage of Ancient Medicine}

Nowadays, a growing number of medicines and drugs are based on formulations that contain natural active principles obtained from the biodiversity that our ancestors (esp. farmers) have conserved for centuries. Many of the most commonlyused medicines are those that have proved useful for various treatments and cures of human ailments and that have been part of local traditions transmitted from generation to generation. A crucial reason for this growth has been the development of new technologies that have improved the sensitivity and efficiency of the processes involved in the isolation and purification of 'new' molecules. This has prompted an expansion of the amount of products and formulations with proven therapeutic principles, which continues to increase every day.

A number of modern herbal formulations have been recently developed by Dexa Laboratories of Biomolecular Science (DLBS) from Indonesia and are currently at different stages of development and commercialization in the pharmaceutical markets [10]. Some examples include: Dismeno $₫$, which helps to relieve pain during menstruation and endometriosis and which has been manufactured from Phaleria macrocarpa (Scheff.) Boerl (Thymelaceae), HerbaVomitz ${ }^{\circledR}$, to treat and prevent nausea and vomiting, manufactured from Zingiber officinale Roscoe (Zingiberaceae), Redacid ${ }^{\circledR}$, to relieve hyperacidity in peptic ulcer, 
manufactured from Cinnamomum burmannii Blume (Lauraceae), Stimuno®, to improve the immune system, manufactured from Phyllanthus niruri L. (Euphorbiaceae), and Herbafit $\AA$, to improve the metabolism, manufactured from Lagerstroemia speciosa (L.) Pers. (Lythraceae). In addition, recent research has focused on the incorporation of dried extracts of five selected Indonesian medicinal plants, namely, Lagerstroemia speciosa (L.) Pers., Phyllanthus niruri L. (Phyllanthaceae), Cinnamomum burmanii Blume, Zingiber officinale Roscoe and Phaleria macrocarpa (Scheff.) Boerl. into orodispersible films (ODFs). Researchers have concluded that ODFs technology is a suitable and efficient novel dosage form for herbal extracts, which need to be optimized in a case-by-case manner [10].

Another example of modern herbal formulation includes the use of standardized extract BG1261® from Buddleja globosa Hope (Buddleja), which exhibits a high content of antioxidant molecules with the ability to reduce the adverse effects originated by Nitrofurantoin (NFT). NFT is an antimicrobial drug for the treatment of lower urinary tract infections, which displays adverse effects related to oxidative stress generated by the enzymatic reduction of NFT. A double-blind randomized-trial at the Hospital Clínico Universidad de Chile demonstrated that extract BG1261® controls the oxidative stress and improves the quality of life of patients during treatment [11].

Surely one of the models of long-established medicine with the greatest expansion and public acceptance is the Traditional Chinese Medicine (hereafter, TCM) whose applications have been increasingly evident in Western countries over the last 30 years [12]. When considering the case of the UK, the Chinese Materia Medica (hereafter, CMM), advocating for the practice of TCM, has been found to regularly trade about 400-500 of raw herbs through suppliers and clinics [13]. CMM validates the use of raw materials mainly from wild flora, which could result in interference among the active compounds found in such raw materials. In this context, the first small-scale macroscopic and quantitative authentication study on CMM was conducted in the UK and resulted in the development of a guide for good practice in TCM herbal drug quality control [14].

Moreover, in Asian and African countries, about $80 \%$ of the population depends on native remedies for their health care, which generally involves raw herbal-preparations [15]. For example, in India around 20,000 medicinal plants have been documented, out of which 7000-7500 are currently used by traditional practitioners [16]. It is widely accepted that traditional medicine involves knowledge that has been passed on from generation to generation with roots in the beliefs and practices of diverse ancient cultures. However, herbal medicines, if used incorrectly, might have adverse effects. In this sense, accurate trials are essential to determine the safety and effectiveness of such health care practices in these traditional systems. Like synthetic drugs, plant-based formulations interact with the functions of molecules, and microorganism present in the human body. An understanding of the mechanism of action is essential then to recognize the accurate actions in order to, consequently, predict and prevent adverse events [17].

The use of medicinal plants to treat antihypertensive conditions serves to illustrate this point [17]. In this regard, researchers have provided clinical evidence and reported mechanisms of action of a total of 16 traditional plants which support hypertension treatments [17]. However, there is still lack of clinical evidence for three plants in regards to the characterization of their mechanism of action. This should be addressed by integrating accessible data from clinical trials to develop evidence-based herbal medications against hypertension. In the meantime, this research offers a valuable opportunity to explore the antihypertensive potential of other plants in the provision of safe and effective curative and/or preventive solutions [17].

Safety studies of herbal formulations then become a challenge to the modern biomedicine. In the case of the symptomatic treatment of osteoarthritis (OA) of the knee, for example, a randomized, double-blind, active-controlled trial was conducted to compare the efficacy of a topical Cryptolepis buchanani oil formulation (CBO) with indomethacin, a topical non-steroidal anti-inflammatory drug [18]. The study, conducted in Thailand, demonstrated that both treatments were tolerated, at the same time that pruritus and rash were observed to occur more frequently in the indomethacin than in the CBO group. It was then concluded that $\mathrm{CBO}$ was as effective as indomethacin for the treatment of $\mathrm{OA}$ of the knee, but with significantly lower rates of adverse reactions [18]. Furthermore, other wild herbs may also have a great potential for pharmaceutical applications if modern technologies are applied for the isolation and purification of active principles. This is the case of Artemisia campestris L. (Asteraceae), a perennial herb commonly known as 'field wormwood' which is widespread in Asia, North America, Europe and North Africa. Recently a review on this species reported the current advances of its ethno medicinal, phytochemical and pharmacological uses worldwide [19].

This herb is rich in phytochemical contents with a spectrum of pharmacological activities thanks to its antioxidant, insecticidal, antibacterial, ant mutagenic, antivenin and antitumor effects. Interestingly, different parts of the plant have variable phytochemical profiles, which could explain its wide bioactive potential. In this regard, the lack of efficient isolation protocols (when conducting bioassays) normally result in the use of crude extracts or essential oils. For this reason, that the optimization of efficient methods to isolate and purify unique chemical components, in addition to the characterization of the mechanisms of action, bioavailability and the pharmacokinetics of isolated pure compounds, will increase the potential and valuation of different formulations of A. campestris L. [19].

As in the nutraceutical industry, the development of pharmacological formulations based mainly on the use 
of plant species is increasingly replacing synthetic drugs by drugs obtained from plant metabolites in laboratorycontrolled conditions. This has been possible due to the current technological improvements in the pharmaceutical industry. However, it is remarkable to note the lack of clinical trials and scientific evidence that in most cases prevent this industry from achieving an appropriate development.

\section{Sustainable Development of Modern Societies: Biodiversity and Traditions}

The concept of sustainability has been subjected to a number of different interpretations since it was first defined as the kind of "development that meets the needs of the present without compromising the ability of future generations to meet their own needs" [20]. Since then, the broadening of different perspectives and the employment of the concept in a variety of contexts (e.g. business, environment and health) has resulted in a lack of clarity, and sometimes consistency, in the utilization of the concept $[21,22]$.

In general terms, sustainability has been strongly regarded depending on whether it is used from a social, economic (equity) or ecological (environmental) standpoint [23]. This three-way approach is often referred to as "the triple-bottom line", especially from an economy-sustainability oriented point of view [24], or as the "three pillars approach" [25-27], where sustainability (often equated to sustainable development) can be achieved by striking an appropriate balance among these three pillars or bottom lines simultaneously.

Within this approach, social sustainability is currently understood as an integrated concept where social issues are strongly linked to economic or environmental issues and where the three are regarded as equally important. As a consequence, providing a definition of social sustainability alone can be problematic, as a number of the features that characterise these three pillars are very closely interrelated. In order to tackle this problem, scholars have proposed a definition of social sustainability that requires the inclusion of the basic principles underlying the integrating idea of a "socially sustainable society", where the members of this kind of society cannot be subdued to the following five main structural obstacles: (1) health, (2) influence, (3) competence, (4) impartiality and (5) meaningmaking [22].

Within this hypothetical framework, the traditional use of biodiversity as developed by ancient human societies is an aspect that has been often neglected by modern western societies [28]. Nowadays, the use of traditional medicines, such as the uña de gato plant (Uncaria tormentosa (Willd), Rubiaceae) [29], is widely embedded in a number of cultures across the world as a standard medicinal practice. Traditional techniques, such as acupuncture, a discipline within TCM, have also managed to expand far beyond its place of origin, becoming a common and widely accepted practice in western medicine [30]. What is more, extreme cases of traditional uses of biodiversity that still remain virtually unknown to modern western science can be found in a few isolated communities in Papua New Guinea [31] and the Amazonian rainforest [32], where trading economies have not yet found their way in. In both cases, such communities still practice their ancient use of biodiversity by manufacturing their own medicines from available plants to meet their life needs.

In regards to environmental sustainability, modern societies can be considered sustainable when they keep the biomass originated in their ecosystems circulating within their own system by way of, for example, recycling their biomass for sustainable fuel usage [33]. This, unfortunately, is in stark contradiction with the export oriented economies that characterize most of the countries around the world today, since sustainability cannot be achieved when societies remove large amounts of biomass from their own ecosystems and export them to be consumed and incorporated into other ecosystems. For this reason, isolated communities like the ones just mentioned remain, from an environmental, social and, to a lesser extent, economic point of view, within the concept of environmental sustainability when they re-circulate and recycle their biomass and energy within their own ecosystem.

In this regard, the main conflict of today's globalised societies begins when globalised economies impose neoliberal practices, such as the establishment of export-oriented markets and unlimited economic growth, as a way to achieve economic development and integration with the rest of the world. As a common example of this kind of behaviour, transnational companies invest overseas for the development, patenting and commercialization of products derived from native fauna and flora species that have been traditionally used with medicinal purposes by foreign isolated communities. Such approach, in most cases, conflicts with the cosmovision and sustainable nature of many of these isolated societies [34]. Therefore, the international community should take responsibility over the protection of the uniqueness and fragility of such communities and their traditional medicinal practices and resources by carefully assessing the ethical principles that should govern any kind of interaction of this nature with them.

\section{Ethical Concerns and the Development of Modern Molecules}

On a practical note, some of the ethical concerns of the modern development and applications of probiotics and functional foods are related to how the bioprocesses involved are researched and optimized [2]. In this light, the demonstration of the health beneficial effects of functional foods needs to be addressed through human trials to provide relevant long-term evidence. In this context, risk assessment analyses, followed by robust statistical processing, should be mandatory in order to consider the ethical concerns involved in these trials. An additional challenge in the evaluation of functional foods is finding a way of ensuring its biological activities for relatively 
long periods of time. The inclusion of functional molecules and benefic microorganisms in an ever growing range of food vehicles must involve product and process adaptations that are able to decrease the risk of functionality change. Altogether, taking these considerations into account should help to better design the human trials that are required to determine the beneficial effects of functional foods $[2,4]$.

From a rather existential point of view, a definition of science is often directly related to the understanding we have of ourselves as human beings. However, these views are strongly shaken by the current environmental crisis we are facing today, which calls for a definition of science based on an understanding of the relationship between human beings and their surrounding environment. From an ethical point of view, science is necessary and is in itself good for human progress and development as long as it is understood holistically, and it advocates for the respect and harmony between human beings and the rest of the planet's biota. This belief, to which some societies are currently trying to intently hold on to due to the environmental crisis that they have created when mistakenly conceiving themselves as the absolute cusp and rulers of nature, is partly based on the respect for the traditions passed on by ancestral cultures who recognized the healthy properties of biodiveristy.

Thus, science must be redefined along these lines [35]. In the context of ancient medical traditions and the discovery of 'modern' molecules, science should no longer be understood exclusively from the point of view of the isolation of certain facts and phenomena that need to be explored for the purposes of experimental analysis and scientific verification. Science, then, must take responsibility for the value and the socio-environmental sustainability of scientific action. Such responsibility would result in the acquisition of scientific knowledge by contemplating the truth of the existence of the world as a whole, in the context of the vulnerability and fragility of life instead of just focusing on the knowledge gained, for example, from the understanding of the function of a particular molecule with therapeutic applications. Overall, the development of such knowledge should not be at the expense of disregarding potential risks for humanity and the environment. In this regard, the isolated communities mentioned above realized the value of life and of social and environmental sustainability long ago and their medicinal practices provide a strong and valuable evidence of this. This kind of knowledge and respect for life makes the co-existence of humans and all life forms inhabiting the planet possible [36].

It is then not enough to define or agree on certain ethical principles to evaluate the goodness of any given research practice exclusively in relation to human beings. Rather, to scientifically improve, for instance, plant molecules for the purpose of improving and maintaining human health, it becomes imperative to consider and value such molecules as the result of biological evolution [37]. To achieve this, heightened importance needs to be given to considerations about the unity of the ecosystem's integrity, the slow pace of biological evolution, and the overall effects of human intervention in the ecosystem with the hope of building a sustainable society for future generations.

In general terms, the purpose of this reflection is to raise some questions which must be addressed in order to evaluate the advantages of improving molecules for the benefit of human beings. Such questions include:

1. Is science looking to promote the medicinal practices that ancestral cultures have developed over the centuries, respecting their cosmovision as a harmonious whole?

2. Do these scientific developments recognize and protect the value of biodiversity as a way of promoting the management of the planet's resources in a sustainable way? or

3. Is the goal simply to improve medicines with the ultimate goal of selling them at the best price and lowest production cost to obtain high profits? Pondering over these matters may play a crucial role in establishing what should be a unified ethical perspective of modern globalised societies towards the historical use of biodiversity anchored in ancient traditions.

\section{Acknowledgement}

Ariel D Arencibia Rodriguez was supported by his project FIC BIP 30386978-0 Región del Maule, and Mariana Lazzaro-Salazar was supported by her project FONDECYT \# 3160104/2016 (CONICYT).

\section{References}

1. Bottazzi V (1983) Other Fermented Dairy Products. Biotechnology. Weinheim, Verlag Chemie pp. 315-363.

2. Jankovic I, Sybesma W, Phothirath P, Ananta E, Mercenier A, et al (2010) Application of probiotics in food products-challenges and new approaches. Curr Opin Biotechnol 21(2): 175-181.

3. Stanton C, Ross RP, Fitzgerald GF, Sinderen VD (2005) Fermented functional foods based on probiotics and their biogenic metabolites. Curr Opin Biotechnol 16(2): 198-203.

4. Burdock GA, Carabin IG, Griffiths JC (2006) The importance of GRAS to the functional food and nutraceutical industries. Toxicology 221(1): $17-27$.

5. Arscott SA, Tanumihardj SA (2010) Carrots of many colors provide basic nutrition and bioavailable phytochemicals acting as a functional food. Comprehensive Reviews in Food Science and Food Safety 9(2): 223-239.

6. Dembitsky VM, Poovarodom S, Leontowicz H, Leontowicz M, Vearasilp S, et al. (2011) The multiple nutrition properties of some exotic fruits: Biological activity and active metabolites. Food Research International 44(7): 1671-1701.

7. Ayala JF, Vega V, Rosas C, Palafox H, Villa JA, et al. (2011) Agro-industrial potential of exotic fruit by products as a source of food additives. Food Research International 44(7): 1866-1874.

8. Basu A, Rhone M, Lyons TJ (2010) Berries: emerging impact on cardiovascular health. Nutr Rev 68(3): 168-177. 
9. Hariram NS, Park SW (2014) Edible berries: Bioactive components and their effecton human health. Nutrition 30: 134-144.

10. Visser JC, Eugresya G, Hinrichs WLJ, Tjandrawinata RR, Avanti C, et al. (2017) Development of orodispersible films with selected Indonesian medicinal plant extracts. Journal of Herbal Medicine 7: 37-46.

11. Leteliera ME, Hidalgo CF, López VM, Ibacache, Pérez C, et al. (2017) BG126®phytodrug improves urinary tract infection treatment with nitrofurantoin in adult women in a double-blind randomized clinical trial. Journal of Herbal Medicine 9: 60-67.

12. Liu XM, Zou JQ, Sheng ZX, Su GQ, Chen SL, et al. (2009) The current global status of Chinese materia medica. Phytotherapy Research 23(10): 1493-1495.

13. Teng L, Shaw D, Barnes J (2015) Characteristics and practices of traditional Chinese medicine retail shops in London, UK: a crosssectional study using an observational approach. J Ethnopharmaco 173: 318-329.

14. Valk JMAVD, Leon CJ, Nesbitt M (2017) Macroscopic authentication of Chinese materia medica (CMM): A UK market study of seeds and fruits. Journal of Herbal Medicine 8: 40-51.

15. Santé O (2005) WHO Global Atlas of Traditional, Complementary and Alternative Medicine. World Health Organization.

16. Samy RP, Pushparaj PN, Gopalakrishnakone P (2008) A compilation of bioactive compounds from Ayurveda. Bioinformation 3(3): 100-110.

17. Rawat P, Kumar SP, Kumar V (2016) Anti-hypertensive medicinal plants and their mode of action. Journal of Herbal Medicine 6(3): 107-118.

18. Hanprasertpong N, Pantong A, Sangdee C, Kunanusorn P, Kasitanon N, et al. (2017) Cryptolepis buchanani oil formulation versus indomethacin solution in topical therapy for osteoarthritis of the knee: A randomized controlled trial. Journal of Herbal Medicine 7:18-26.

19. Dib I, Angenot L, Mihamou A, Ziyyat PA, Tits M, et al. (2017) Artemisia campestris L.: Ethnomedicinal, phytochemical and pharmacological review. Journal of Herbal Medicine 7: 1-10.

20. Brundtland GH (1987) World commission on environment and development (1987): Our common future. World Commission for Environment and Development. World Health Organization, October 2006. Constitution of the World Health Organization e Basic Documents. Supplement, forty-fifth ed.

21. Peterson $N$ (2016) Introduction to the special issue on social sustainability: integration, context, and governance. Sustainability: Science, Practice and Policy 12(1): 3-7.

22. Missimer M, Robèrt KH, Broman G (2017) A strategic approach to social sustainability-Part 2: a principle-based definition. Journal of Cleaner Production 140(part 1): 42-52

23. Brown BJ, Hanson ME, Liverman DM, Merideth RW (1987) Global sustainability: toward definition. Environmental Management 11(6): 713-719.

24. Hacking T, Guthrie P (2008) A framework for clarifying the meaning of Triple Bottom-Line, Integrated, and Sustainability Assessment. Environmental Impact Assessment Review 28(2-3): 73-89.

25. Pope J, Annandale D, Morrison-Saunders A (2004) Conceptualising sustainability assessment. Environmental Impact Assessment Review 24(6): 595-616

26. Gibson RB (2006) Beyond the pillars: sustainability assessment as a framework for effective integration of social, economic and ecological considerations in significant decision-making. Journal of Environmental Assessment Policy and Management 8(03): 259-280.

27. Hansmann R, Mieg HA, Frischknecht P (2012) Principal sustainability components: empirical analysis of synergies between the three pillars of sustainability. International Journal of Sustainable Development \& World Ecology 19(5): 451-459.

28. Haak H, Hardon A (1988) Indigenised pharmaceuticals in developing countries: widely used, widely neglected. The Lancet 2(8611): 620621.

29. Keplinger K, Laus G, Wurm M, Dierich MP, Teppner H, et al. (1998) Uncaria tomentosa (Willd.) DC-ethno medicinal use and new pharmacological, toxicological and botanical results. J Ethnopharmacol 64(1): 23-34.

30. Ezzo J, Berman B, Hadhazy VA, Jadad AR, Lao L, et al. (2000) Is acupuncture effective for the treatment of chronic pain? A systematic review. Pain 86(3): 217-225.

31. Munn ND (1992) The fame of Gawa: A symbolic study of value transformation in a Massim (Papua New Guinea) society. Duke University Press, UK, p.352.

32. Davis EW, Yost JA (1983) The ethnomedicine of the Waorani of Amazonian Ecuador. Journal of Ethnopharmacology 9(2-3): 273-297.

33. Rashid N, Rehman MSU, Han JI (2013) Recycling and reuse of spent microalgal biomass for sustainable bio fuels. Biochemical Engineering Journal 75: 101-107.

34. Sibanda B (2001) CAMPFIRE: Tonga cosmovision and indigenous knowledge. In: Balram S, Dragićević S (Eds), Conflict and Cooperation in Participatory Natural Resource Management, Palgrave Macmillan, UK, pp. 113-128.

35. González OJA (2008) La ética y el medio ambiente. Ciencias 91: 4-15.

36. Gudynas, E (2004) Ecología, Economía y Ética del Desarrollo Sostenible. In: $\left(5^{\text {th }}\right.$ edn $)$, CLAES, Montevideo.

37. Universidad Alberto Hurtado (2015) Cuidemos la casa común: una ecología integral. Informe Ethos, p. 106.

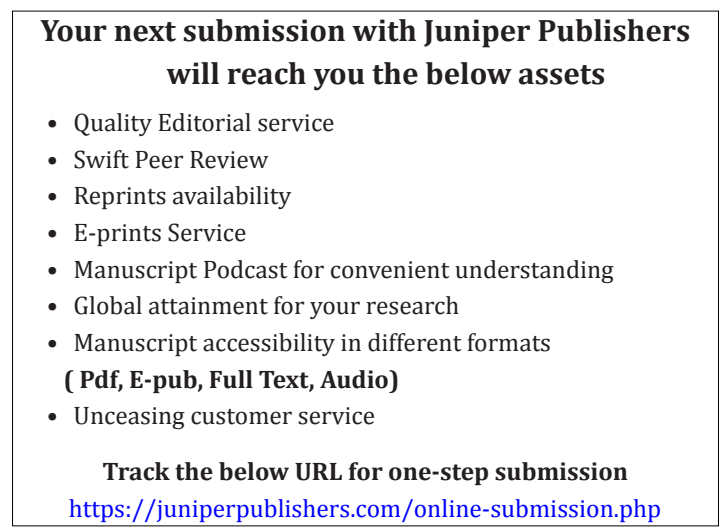

